UDC 615.015.11: 541.69

LBC 28

\title{
METHODOLOGY OF VALIDATION OF IN SILICO 3D MODELS OF PHARMACOLOGICALLY RELEVANT PROTEINS-TARGETS
}

\author{
Laura R. Yanalieva
}

Volgograd State Medical University, Volgograd, Russian Federation

Pavel M. Vasilyev

Volgograd State Medical University, Volgograd, Russian Federation

Andrey N. Kochetkov

Volgograd State Medical University, Volgograd, Russian Federation

\begin{abstract}
The article studies the development of methodology and results of validation of in silico 3D models of pharmacologically relevant target proteins on the example of protein kinase $\mathrm{C}$ theta. Using the IUPHAR / BPS database, information has been found about 5 reference inhibitors PRKCQ, recognized by the world scientific community. According to the received data, 3 most valid PRKCQ models (PDB-codes: 5F9E, 2JED, 4RA5) have been selected, which can later be used for docking of new inhibitors.
\end{abstract}

Key words: 3D models of target proteins, biosensors, reference inhibitors, docking, validation, protein kinase.

УДК 615.015.11: 541.69

ББК 28

\section{МЕТОДОЛОГИЯ ВАЛИДАЦИИ IN SILICO 3D-МОДЕЛЕЙ ФАРМАКОЛОГИЧЕСКИ РЕЛЕВАНТНЫХ БЕЛКОВ-МИШЕНЕЙ ${ }^{1}$}

\author{
Лаура Рифатовна Яналиева
}

Волгоградский государственный медицинский университет, г. Волгоград, Российская Федерация

Павел Михайлович Васильев

Волгоградский государственный медицинский университет, г. Волгоград, Российская Федерация

\section{Андрей Николаевич Кочетков}

Волгоградский государственный медицинский университет, г. Волгоград, Российская Федерация

Аннотация. В статье рассмотрены разработка методологии и результаты валидации in silico 3D-моделей фармакологически релевантных белков-мишеней на примере протеинкиназы С тета. С помощью базы данных IUPHAR/BPS найдена информация о 5 общепризнанных мировым научным сообществом референсных ингибитоpax PRKCQ. Согласно полученным данным были отобраны 3 наиболее валидных модели PRKCQ(PDB-коды: 5F9E, 2JED, 4RA5), которые в дальнейшем можно использовать для поиска методом докинга ее новых ингибиторов.

Ключевые слова: 3D-модели белки-мишени, биомешени, референсные ингибиторы, докинг, валидация, протеинкиназа.

В настоящее время для поиска новых лекарственных веществ широко применяются методы in silico, в основе которых лежит ком- пьютерное моделирование белок-лигандного взаимодействия в сайте связывания соответствующей биомишени. Валидность использу- 
емых 3D-моделей белков-мишеней во многом определяет результаты такого моделирования. В доступных интернет-источниках отсутствует информация об адекватности тех или иных $3 \mathrm{D}$-моделей белков как релевантных мишеней для поиска соединений с заданной фармакологической активностью. Таким образом, проблема валидации 3D-моделей белков-мишеней является весьма актуальной при поиске in silico новых фармакологически активных веществ.

Изоформа тета протеинкиназы C (PRKCQ) экспрессируется относительно селективным образом в Т-лимфоцитах. Вовлеченность PRKCQ в активацию Т-клеток, пролиферацию и продуцирование цитокинов отражает существенную роль этого изотипа в индуцировании сигнальных путей, приводящих к активации транскрипционного фактоpa NF-kB, который запускает ряд патологических процессов.

Целью данной работы является разработка методологии валидации in silico 3D-моделей фармакологически релевантных белков мишеней на примере протеинкиназы $\mathrm{C}$ тета.

Для достижения этой цели необходимо было решить следующие задачи:

1. Провести поиск первичной информации о PRKCQ.

2. Получить данные об экспериментальных 3D-моделях PRKCQ.

3. Найти сведения о референсных ингибиторах PRKCQ.

4. Выявить неактивные в отношении PRKCQ соединения, структурно наиболее сходные с референсными ингибиторами PRKCQ.

5. Определить пространственное расположение специфического сайта связывания PRKCQ.

6. Построить оптимизированные 3D-модели референсных ингибиторов PRKCQ и неактивных веществ.

7. Выполнить докинг 3D-моделей референсных ингибиторов PRKCQ и неактивных веществ в сайт связывания PRKCQ.

8. Выявить наиболее валидные 3D-модели PRKCQ.

Первичная информация о PRKCQ была взята из базы знаний по белкам и их функциям UniProtKB [6]. В результате их анализа из банка данных PDBe [4] были получены координатные файлы и сведения о пространственной структуре пяти экспериментальных $3 \mathrm{D}$-моделей белок-лигандных комплексов PRKCQ (PDB-коды: 1XJD, 2JED, 4Q9Z, 4RA5, 5F9E). В базе данных IUPHAR/BPS [2] найдена информация о пяти общепризнанных мировым научным сообществом референсных ингибиторах PRKCQ: Sotrastaurin, PKC theta inhibitor 14 (Y-27632), GSK690693, Compound-41, Midostaurin (РКC412). Структурно сходные с этими ингибиторами пять неактивных веществ (по одному на каждый референс) были определены с помощью оригинальной программы Microcosm BioS, в coставе которой имеется представительный банк данных по таргетной активности новых химических соединений. Анализ пространственного расположения в найденных 3D-моделях специфического сайта связывания PRKCQ проводился с помощью оригинальной программы BestSites. Выявлено 17 ключевых связывающих аминокислот, ограничивающих пространство каталитического сайта PRKCQ. 3D-модели референсных ингибиторов PRKCQ и неактивных веществ были построены сначала с помощью методов молекулярной механики в программе MarvinSketch 15.6.15 [1], а затем оптимизированы полуэмпирическим квантово-химическим методом РМ7 в программе MOPAC2012 [3]. Докинг всех 10 соединений в сайт PRKCQ выполняли с помощью программы AutoDock Vina 1.1.1 [5], каждую молекулу по пять раз. Для каждой из 5 исследуемых 3D-моделей PRKCQ по 5 референсам и 5 неактивным соединениям вычисляли средние, минимальные и максимальные значения энергии докинга, а затем их попарные разности $\Delta \mathrm{E}_{\text {Референсов }}-\Delta \mathrm{E}_{\text {Неактивных }}$. Метрикой валидности 3D-моделей PRKCQ служила сумма 3 таких разностей для средней, минимальной и максимальной энергий докинга $\Delta \mathrm{E}_{\text {Валидации }}$ Этот параметр отражает общее количественное различие между аффинностью референсных ингибиторов PRKCQ и аффинностью структурно сходных с ними неактивных соединений. Чем меньше величина $\Delta \mathrm{E}_{\text {Валидации, }}$ тем более валидной считалась 3D-модель.

По результатам расчетов отобраны 3 наиболее валидные модели PRKCQ (PDBкоды: 5F9E, 2JED, 4RA5), имеющие значения 


\section{ЭКОЛОГИЯ И ПРИРОДОПОЛЬЗОВАНИЕ}

$\Delta \mathrm{E}_{\text {Валидации }} 4.59,4.12$ и 3.36 ккал/моль (соответственно). Найденные валидные 3D-модели в дальнейшем будут использованы для поиска методом докинга новых ингибиторов PRKCQ.

\section{Выводы}

1. Разработана методика валидации in silico 3D-моделей фармакологически релевантных белков-мишеней, основанная на оценке суммы разностей средней, минимальной и максимальной энергий докинга референсных соединений и структурно близких к ним неактивных веществ.

2. Методика применена для валидации 3D-моделей протеинкиназы C тэта.

3. Выявлены 3 валидных экспериментальных 3D-модели протеинкиназы C тэта, которые в дальнейшем будут использованы для поиска методом докинга ее новых ингибиторов.

4. Методика может быть использована для валидации 3D-моделей других белковмишеней, релевантных иным видам фармакологической активности.

\section{ПРИМЕЧАНИЕ}

1 Работа выполнена при финансовой поддержке Российского фонда фундаментальных исследований (проект 18-015-00499).

\section{СПИСОК ЛИТЕРАТУРЫ}

1. ChemAxon // ChemAxon Limited. - Electronic text data. - Mode of access: https://chemaxon.com/.

2. IUPHAR // Union of Basic and Clinical Pharmacology. - Electronic text data. - Mode of access: https://www.iuphar.org/.

3. MOPAC// Stewart Computational Chemistry. Electronic text data. - Mode of access: http:// openmopac.net/.

4. PDBe // Protein Data Bank in Europe. Electronic text data. - Mode of access: http:// www.ebi.ac.uk/pdbe/.

5. Trott, O. AutoDock Vina: improving the speed and accuracy of docking with a new scoring function, efficient optimization and multithreading / A. J. Olson, O. Trott // J. Comp. Chem. - 2010. - Vol. 31, Iss. 2. P. 455-461.

6. UniProtKB // UniProt Consortium. Electronic text data. - Mode of access: https:// www.uniprot.org/.

\section{Information about the Authors}

Laura R. Yanalieva, Assistant, Department of Pharmacology and Bioinformatics, Volgograd State Medical University, Pavshikh bortsov Sq., 1, 400131 Volgograd, Russian Federation, post@volgmed.ru

Pavel M. Vasilyev, Doctor of Sciences (Biology), Professor, Department of Pharmacology and Bioinformatics, Senior Researcher of Research Institute of Pharmacology, Volgograd State Medical University, Pavshikh bortsov Sq., 1, 400131 Volgograd, Russian Federation, pvassiliev@mail.ru.

Andrey N. Kochetkov, Volgograd State Medical University, Pavshikh bortsov Sq., 1, 400131 Volgograd, Russian Federation, yanalieva.laura@yandex.ru.

\section{Информация об авторах}

Лаура Рифатовна Яналиева, старший лаборант, кафедра фармакологии и биоинформатики, Волгоградский государственный медицинский университет, пл. Павших Борцов, 1, 400131 г. Волгоград, Российская Федерация, yanalieva.laura@yandex.ru.

Павел Михайлович Васильев, доктор биологических наук, старший научный сотрудник, кафедра медицины катастроф, Волгоградский государственный медицинский университет, пл. Павших Борцов, 1, 1400131 г. Волгоград, Российская Федерация, pvassiliev@mail.ru.

Андрей Николаевич Кочетков, Волгоградский государственный медицинский университет, пл. Павших Борцов, 1, 1400131 г. Волгоград, Российская Федерация, yanalieva.laura@yandex.ru. 